\title{
Prevalence of Intestinal Parasitic Infections among School Children of Dadeldhura District, Nepal
}

\author{
${ }^{1}$ Bishnu Raj Tiwari, ${ }^{2}$ Ranju Chaudhary, ${ }^{2}$ Nabaraj Adhikari, ${ }^{3}$ Sailesh Kumar Jayaswal, \\ ${ }^{4}$ Thakur Prasad Poudel, ${ }^{5}$ Komal Raj Rijal \\ ${ }^{1}$ School of Health and Allied Sciences, Pokhara University, Kaski, Nepal \\ ${ }^{2}$ Department of Microbiology, National College, Tribhuvan University, Kathmandu, Nepal \\ ${ }^{3}$ HDCS-TEAM Hospital, Dadeldhura, Nepal \\ ${ }^{4}$ Department of Microbiology, Nepalgunj Medical College, Nepalgunj, Banke, Nepal \\ ${ }^{5}$ Central Department of Microbiology, Tribhuvan University, Kathmandu, Nepal
}

\begin{abstract}
Intestinal parasitic infestations are a common finding in the developing world, however, the patterns of parasitic distribution and rates are different elsewhere. The prevalence of intestinal parasitic infestation and chemical analysis of stool sample of the school children of age group 4-12 years in Dadeldhura district, far western region of Nepal. Out of 530 stool samples, 165 $(31.13 \%)$ were found to be intestinal parasites positive. Among the total parasites, Hymenolepsis nana (46.56\%) and Giardia lamblia (7.47\%) were found in high prevalence as helmiths and protozoa respectively. Among the total stool samples 159 (30\%) showed positive occult blood test. The prevalence of parasitic infection was found high in the children of age group 4-6 years $(38.18 \%)$ than others though the result was not significant statistically $(P>0.05)$. Highest prevalence of parasites was found in those not following the hygienic conditions (36.17\%) than those following (18.83\%). Similarly, high proportion of the parasites were found in children having gastrointestinal symptoms (49.23\%) than in children without the gastrointestinal symptoms $(13.70 \%)$ though the result was not significant statistically $(P>0.05)$. The study showed the children using the water directly from the source had higher prevalence of parasites (32.13\%) than those using treated water (14.28\%). This study presents the high prevalence of stool parasites in school going children of Dadeldhura district.
\end{abstract}

Key words: Parasitic infection, School children, Stool samples, Dadeldhura, Nepal.

Corresponding address: Bishnu Raj Tiwari, School of Health and Allied Sciences, Pokhara University, Kaski, Nepal.

E-mail: bishnurajtiwari@gmail.com

\section{INTRODUCTION}

Intestinal parasitic infections are among the major problems of public health in developing countries. Approximately 3.5 billion people are infected by intestinal parasites and around 450 million children are ill due to these infections. ${ }^{1}$ Intestinal parasitosis alone is one of the most common public health problems in all over Nepal. ${ }^{2,3,4}$ The distribution and prevalence of the various intestinal parasites species depend on social, geographical, economical and inhabitant customs. Studies on human parasitic infections have demonstrated a common relationship between parasitic infections and lower socio-economic status of the region. ${ }^{5}$ So periodic epidemiological studies and transmission dynamics in parasitic infections will provide more accurate understanding. ${ }^{6}$

Ascaris lumbricoides, Trichuris trichiura and Hookworms, collectively referred to as soil-transmitted helminths (STHs), are the most common intestinal parasites. Ascaris lumbricoides is the largest and the most common helminth parasitizing the human intestine. Giardia lamblia is the most prevalent protozoan parasite worldwide. ${ }^{7}$

It is estimated that soil transmitted helminthes ( $\mathrm{STH})$ alone infect over one billion people in the world. Many of them were infected by more than one species of STH. It has been estimated that 65,000 deaths occur due to Ascaris lumbricoides, 60,000 due to hookworms and 70,000 due to Trichuris trichiura each year and STH mainly affect children leading to their poor growth, reduced physical activity, impaired cognitive function and learning ability. In Nepal, STH infection has remained as one of the significant health problems. The prevalence rate approaches nearly one hundred percent in some areas and been associated with anaemia and malnutrition. Even now intestinal helminthes infection ranks fourth in top-ten diseases in Nepal. ${ }^{1,8}$ Present study was designed to study the prevalence of intestinal parasites among village school children of Dadeldhura district among village school children of rural place, Dadeldhura, far West region of Nepal.

\section{MATERIALS AND METHODS}

The study was cross sectional study done amongst the school going children. The area of this study was from different villages of Dadeldhura district and the samples were processed in the Microbiology laboratory of Team Hospital, Dadeldhura. The study was conducted from December 2009 
to March 2010. A total of 530 stools samples from children of various schools of Dadeldhura district were randomly collected. Children of age group 4-12 years were selected for study. The data was collected from the children using questionnaire on age, sex, water sources, personal hygiene habits and presence of gastrointestinal tract symptoms during the school hour at that very day. Children/attendance of children were requested to collect about $30 \mathrm{gms} / 30 \mathrm{ml}$ of the stool sample avoiding contamination of urine, water and other substances in a container. Single specimen was collected from each individual. The samples were processed using standard methodology for the physical, chemical and microscopic examination of stool sample ${ }^{9}$. Data were analyzed by using Microsoft excel sheet and SPSS 11.5 version.

\section{RESULTS}

A total of 530 stool samples were examined macroscopically, out of total samples, $468(88.30 \%)$ and $430(81.10 \%)$ were normal in colour and consistency respectively. Mucous was present in $43(8.10 \%)$ samples but none of the sample were seen to contain blood.

Table 1: Physical properties of stool samples.

\begin{tabular}{|l|l|c|c|}
\hline Properties & \multicolumn{1}{|c|}{ Examination } & Total (n) & $\mathbf{\%}$ \\
\hline \multirow{2}{*}{ Colour } & Normal & 468 & $88.30 \%$ \\
\cline { 2 - 4 } & Abnormal & 62 & $11.70 \%$ \\
\hline \multirow{2}{*}{ Consistency } & Normal & 430 & $81.10 \%$ \\
\cline { 2 - 4 } & Abnormal & 100 & $18.90 \%$ \\
\hline \multirow{2}{*}{ Blood } & Presence & 0 & $0 \%$ \\
\cline { 2 - 4 } & Absence & 530 & $100 \%$ \\
\hline \multirow{2}{*}{ Mucus } & Presence & 43 & $8.10 \%$ \\
\cline { 2 - 4 } & Absence & 487 & $91.90 \%$ \\
\hline \multirow{3}{*}{ Worms } & $\begin{array}{l}\text { Ascaris lumbricoides } \\
\text { (Round worm) }\end{array}$ & 5 & $0.90 \%$ \\
\cline { 2 - 4 } & Absence & 525 & $99.10 \%$ \\
\hline
\end{tabular}

Of the total 530 stool samples, occult blood test was positive in 159. Out of total positive occult blood test, 93(58.49\%) stool samples showed parasitic infection. Similarly, among the total negative occult blood test, 72(19.40\%) stool sample showed parasitic infection. The result was not significant statistically $(\mathrm{P}>0.05)$.

Table 2: Parasitic infection according to occult blood test.

\begin{tabular}{|l|c|c|c|}
\hline Occult blood test & Total $(\mathbf{N})$ & Parasitic infection & p value $(\chi)^{\mathbf{2}}$ \\
\hline Positive & 159 & $93(58.49 \%)$ & \multirow{2}{*}{$\mathrm{p}<0.001$} \\
\cline { 1 - 3 } Negative & 371 & $72(19.40 \%)$ & \\
\cline { 1 - 3 } Total & 530 & $165(31.13 \%)$ & \\
\hline
\end{tabular}

Among a total of 530 stool samples, 165 samples (31.13\%) were found parasites. The prevalence of parasitic infection in case of males was found to be $98(30.40 \%)$ (Table 3$)$. The result was not significant statistically $(\mathrm{P}>0.05)$.
Table 3: Distribution of parasites in different genders.

\begin{tabular}{|l|c|c|c|}
\hline Gender & Total $(\mathbf{N})$ & Positive $(\mathbf{N})$ & p value $(\chi)^{\mathbf{2}}$ \\
\hline Male & 322 & $98(30.40 \%)$ & \\
\cline { 1 - 2 } Female & 208 & $67(32.20 \%)$ & \multirow{2}{*}{$\mathrm{p}>0.05$} \\
\hline Total & 530 & $165(31.13 \%)$ & \\
\hline
\end{tabular}

Of the total 530 school children, the highest prevalence of parasitic infection was found in the children of age group 4-6 years, (42) 38.18\% (Table 4) and result was not significant statistically $(\mathrm{P}>0.05)$.

Table 4: Parasitic infections in different age groups.

\begin{tabular}{|l|c|c|c|}
\hline \multicolumn{1}{|c|}{ Age group } & Total $(\mathbf{n})$ & Positive $(\mathbf{n})$ & p value $(\chi)^{\mathbf{2}}$ \\
\hline 4-6 years & 110 & $42(38.18 \%)$ & \\
\cline { 1 - 2 } 7-9 years & 146 & $47(32.19 \%)$ & \multirow{2}{*}{$\mathrm{p}>0.05$} \\
\cline { 1 - 2 } 10-12 years & 274 & $76(27.73 \%)$ & \\
\cline { 1 - 3 } Total & 530 & $165(31.13 \%)$ & \\
\hline
\end{tabular}

The prevalent species were Hymenolepis nana 81 (46.56\%), Hookworm 48 (27.58\%), Ascaris lumbricoides 31 (17.82\%), Giardia lamblia $13(7.47 \%)$ and Trichuris trichiura 1 $(0.57 \%)$.

Table 5: Intestinal parasites detected among the school children.

\begin{tabular}{|c|l|r|}
\hline S.N. & Parasites detected & Total $(\mathbf{N}) / \%$ \\
\hline 1 & Hymenolepis nana & $81(46.56 \%)$ \\
\hline 2 & Hookworm & $48(27.58 \%)$ \\
\hline 3 & Ascaris lumbricoides & $31(17.82 \%)$ \\
\hline 4 & Giardia lamblia & $13(7.47 \%)$ \\
\hline 5 & Trichuris trichiura & $1(0.57 \%)$ \\
\hline & Total & $174(100.0 \%)$ \\
\hline
\end{tabular}

\section{DISCUSSION}

The parasitic infection is a common cause of morbidity and mortility in paediatric population in tropical countries. The prevalence of intestinal parasites in children varies in different regions of the world. It is particularly high in poor and developing countries due to use of contaminated drinking water, inadequate sanitary conditions and poor personal hygiene. ${ }^{10}$

In this study, total of 530 stool sample 468(88.30\%) samples were of normal, for the consistency of stool, $430(81.10 \%)$ were of normal consistency, blood were not seen in total stool sample, out of total sample, in 43(8.10\%) stool sample mucus were present, for the presence of worms, out of total sample only in $5(0.90 \%)$ stool sample, Ascaris lumbricoides were seen by macroscopic examination of stool sample. In this study 159 stool samples showed positive occult blood test. Of total positive occult blood test, 93 (58.49\%) stool sample showed parasitic infection. 
The present study demonstrated that positive test occult blood test during routine analysis was correlated with the intestinal parasitic infection. However, as test occult blood test is widely used in Nepal, more awareness for the public about importance of restricting some foods and drugs intake prior fecal occult blood test is needed and our result with occult blood test is consistent with the Wakid et al.,. ${ }^{11}$ In this study, the overall prevalence of intestinal parasites among village school children was $31.13 \%$, which is consistent with the findings of Wadood et al., and Tadesse..$^{10,12}$ The most common intestinal parasites identified in the present study was $H$. nana $(46.56 \%)$ which is noteworthy, as reported such high rates of this cestode by Sharma et al., Adhikari et al., Shrestha et. al.,. ${ }^{13,14,15}$ Higher prevalence of hymenolepiasis is reported by Wadood et al., from Pakistan i.e. 34\%, Martinez et al., from Mexico i.e. 22.6\%, and by Mirdha et al., from India i.e. $9.9 \% .^{10,16,17} H$. nana prevalence noticeably decreased with increasing age. Therefore, it may be associated with the poor sanitation and low socio-economic status in the community. This high prevalence in present study may be due to faecooral route by ingesting of eggs from contaminate hands, poor personal hygiene and poor environmental hygiene that contribute to result such high prevalence among the children. The prevalence of Hookworm was also very high (27.58), which are in accordance with reports from Chhakda et. al.,. ${ }^{18}$ Higher prevalence of Hookworm infection is associated with personal hygiene and maternal education. In the present study, the prevalence of the parasites in children having gastrointestinal symptoms was $128(49.23 \%$ ) and in children without the gastrointestinal symptoms were $37(13.70 \%)$. The result shows a significant association between gastrointestinal symptom and parasitic infection, which is very consistent with the findings of Adhikari et. al.,. ${ }^{14}$

\section{CONCLUSION}

The present study reveals that the health status in this district of school going children was limited due to the relatively poor hygiene and sanitary conditions. Thus, prompt preventive measures should be taken for the eradication of high infestation, rate which should include public health education, safe water supply, improve sanitation and personal hygiene practices.

\section{ACKNOWLEDGEMENT}

We would like to thank the members of Team Hospital Dadeldhura, for providing laboratory facilities in the hospital. We are also thankful to the school children of Dadeldhura district for providing stool samples and necessary information for this research work.

\section{REFERENCES}

1. WHO. World Health Report, Conquering Suffering enriching humanity. 2000.

2. Estevez EG, Levine JA and Warren J Intestinal parasites in a remote village in Nepal, J Clinical Microbiol. 1983); 17:160-1.

3. Rai SK, Gurung CK. Intestinal parasitic infections in high school children of Birgunj City, J Inst. Medical (Nepal). 1986; $17: 134-42$.

4. Ishiyama S, Rai SK, Ono K, Uga S. Small scale study on intestinal parasitosis in a remote hilly village in Nepal, NMCJ. 2003;15:28-30.

5. WHO. Winning the fight against neglected tropical diseases. 2006.

6. WHO, World Health Report, Controlling disease due to helminthes infections. 2008.

7. Mehraj V. Prevalence of and factors associated with intestinal parasites among children from 1 to 5 years of age in an urban slum of Karachi, (Ph.D Thesis) Age Khan University, Department of Community Health Sciences. 2006.

8. Rai SK, Hirai K, Abe A, Ohno Y. Infectious Diseases and Malnutrition Status in Nepal; an Overview, Mal J Nut. 2002; 8(2):191-200

9. Chatterjee KD. Parasitology (protozoology and Helminthology) in relation to clinical medicine. 1998

10. Wadood AU, Bari A, Rhman AU and Qasin KF. Frequency of intestinal parasite infestation in children hospital, Quetta, Pakistan J Medical Res. 2005; 44:87-8

11. Wakid MH. Fecal Occult Blood Test and Gastrointestinal Parasitic Infection, J Parasitol Res. 1010; 10:1155

12. Tadesse G. The prevalence of intestinal helminthic infections and associated risk factors among school children in Babile town, Eastern Ethiopia, Ethiop J Health Dev. 2005; 19(2):140-7.

13. Sharma BK, Rai SK, Rai DR, Chaudhari DP. Prevalence of intestinal parasitic infestation in school children in the North eastern part of Kathmandu valley, Nepal, NMCJ. 2004; 35:501-5.

14. Adhikari N, Bomjan R, Khatri DB, Joshi DR, Dhakal P, Lekhak B. Intestinal Helminthic infections among school children in Kathmandu valley, JNHRC. 2007; 5:17-22

15. Shrestha SK, Rai SK, Vitrakoti R, Pokharel P. Parasitic infection in school children in Thimi area, Kathmandu valley, J of NAMLS. 2009; 10(1):31-3

16. Martinez-Barbabosa I, Gutierrez-Cardenas E M, Gaona E, Shea M. The prevalence of Hymenolepis nana in schoolchildren in a bicultural community, Rev Biomed. 2010; 21:21-7.

17. Mirdha BR and Samantray JC. Hymenolepis nana: A Common Cause of Paediatric Diarrhoea in Urban Slum Dwellers in India, J of Tropical Ped. 2002; 48:331-4.

18. Chhakda T, Muth S, Socheat D and Odermalt P. Intestinal parasites in school aged children in villages boarding Tonle Sap Lake, Cambodia, Southeast Asian J Tropical Medical Public Health. 2006; 37:859-864. 